$\begin{array}{llllllllllllllllllll}\text { A C T A } & \text { C H E M I C A } & \text { S C A N D I N A V I C A } & 18 & (1964) & 174-184\end{array}$

\title{
Synthesis of 2-Alkoxy-1,3,4-thiadiazoles
}

\author{
EVA ÅERBLOM andKURT SKAGIUS
}

Research Division, AB Pharmacia, Uppsala, Sweden

\begin{abstract}
2-Alkoxy-5-(alkyl)amino-1,3,4-thiadiazoles have been prepared by oxidation of the corresponding 1-alkoxythiocarbonyl-4-(alkyl)-3thiosemicarbazides with hydrogen peroxide. Attempts to prepare alkoxyderivatives from 2-chloro-5-(acyl)amino-1,3,4-thiadiazoles by nucleophilic substitution of the chlorine atom only gave alkoxy derivatives in some cases. The thiadiazole structure of the alkoxy derivatives was proved by hydrolysis experiments and IR-spectra. Acid hydrolysis gave the corresponding thiadiazolones and alkaline hydrolysis caused ring rupture. The Sandmeyer reaction of the alkoxy derivatives gave 5-chloro-1,3,4-thiadiazoline-2-one. Alkylation with alkyl halides and alkyl $p$-toluenesulphonates gave 4-alkyl derivatives.
\end{abstract}

Gince some sulphanilamido heterocyclics with an alkoxy substituent on the Wheterocyclic ring, e.g. 3-sulphanilamido-6-methoxy-pyridazine, ${ }^{1}$ were found to have antibacterial activity of long duration, it was of interest to synthesize 2-alkoxy-5-sulphanilamido-1,3,4-thiadiazoles and examine their antibacterial activities. A series of alkoxythiadiazoles were prepared in connection with this work.

Only a few 2-alkoxy-1,3,4-thiadiazoles have been described in the literature..$^{2-6}$ Most of these have been obtained by alkylation of the corresponding thiadiazolones and the alkoxy structure has been claimed without further proof. It is known, however, that alkylation of thiadiazolones can give both $\mathrm{O}$ - and $\mathrm{N}$-alkyl derivatives, and 2-acylamino-1,3,4-thiadiazoline-2-one has been shown ${ }^{7}$ to give an $\mathrm{N}$-alkyl derivative. Since 2-imino-1,3,4-thiadiazolidine-5-one is also expected to give $\mathrm{N}$-alkyl derivatives, the alkylation reaction seems to be of little value in the preparation of 2-amino-5-alkoxy-1,3,4-thiadiazoles.

Because of the strong electronegative character of the thiadiazole nucleus, the chlorine atom of 2-chloro-5-amino-1,3,4-thiadiazoles is activated and can be readily substituted by nucleophilic agents, for example, primary and secondary amines. ${ }^{8}$ Thus, 2-amino-5-chloro-1,3,4-thiadiazole (I) should give the expected alkoxy derivatives when heated with alkoxides. In practice, a reaction takes place in which the thiadiazole ring breaks and high-melting polymers are obtained. However, with phenol as a solvent and sodium phenoxide as reactant, (I) gives 2-amino-5-phenoxy-1,3,4-thiadiazole (II). (Scheme 1). 


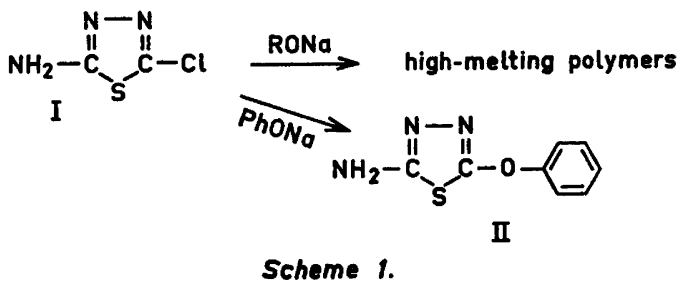

The thiadiazole nucleus of the acylated derivatives of 2-chloro-5-amino1,3,4-thiadiazole is much more stable to alkali and alkoxides than the unsubstituted amine (I). On the other hand, the chlorine atom is not very reactive and long reaction times are required for substitution of the halogen by alkoxides. When 2-chloro-5-acetylamino-1,3,4-thiadiazole (III) was reacted with sodium methoxide for $14 \mathrm{~h}, 2$-methoxy-5-acetylamino-1,3,4-thiadiazole (IV) was obtained in a yield of $21 \%$ (Scheme 2). The low yield is probably due to the sensitivity of the alkoxythiadiazole to alkali and alkoxides. Hydrolysis experiments with the methoxy and ethoxy derivatives show that the ethoxy derivative is even more sensitive and, accordingly, 2-ethoxy-5-acetylamino1,3,4-thiadiazole could not be obtained from 2-chloro-5-acetylamino-1,3,4thiadiazole (III) and sodium ethoxide.

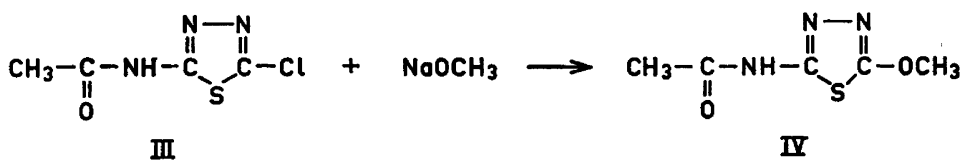

Scheme 2.

Ring"closure of 1-alkoxythiocarbonyl-3-thiosemicarbazides (VI) constitutes a more successful way to the alkoxythiadiazoles. The thiosemicarbazides (VI) were prepared from the corresponding carboxymethyl alkylxanthates (V) and thiosemicarbazide. The carboxymethyl alkylxanthates (V) were synthesized as described by Holmberg ${ }^{9}$ for the methyl and ethyl homologues of (V) (Scheme 3).
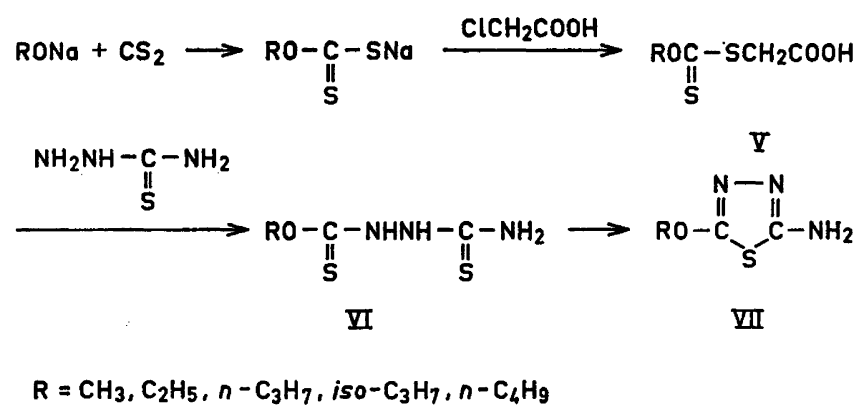

Scheme 3.

Acta Chem. Scand. 18 (1964) No. 1 
Generally, ring closure of substituted thiosemicarbazides, for example, 1-carbamoyl-thiosemicarbazide, ${ }^{10}$ 1-thiocarbamoyl-thiosemicarbazide ${ }^{11}$ and 1-amidino-thiosemicarbazide, ${ }^{12}$ gives thiadiazoles in acid and triazoles in alkali.

$$
\mathrm{R}-\mathrm{NH}-\mathrm{C}-\mathrm{NHNH}-\underset{\mathrm{I}}{\mathrm{C}}-\|_{\mathrm{X}}^{\mathrm{C}}-\mathrm{NH}_{2} \quad \mathrm{X}=\mathrm{O}, \mathrm{S}, \mathrm{NH}
$$

When 1-alkoxythiocarbonyl-thiosemicarbazides (VI) were heated with acid, ring closure was not obtained; instead they were hydrolysed to thiosemicarbazide.

Substituted dithiocarbonylhydrazides have been reported to give thiadiazole derivatives on warming. Wangel ${ }^{5}$ synthesized 2-phenyl-5-ethoxy-1,3,4thiadiazole from 1-ethoxythiocarbonyl-2-phenylthiocarbonyl-hydrazide. The ring closure occurred already at room temperature. Also, Wheeler et al..$^{3}$ have reported that 1-ethoxythiocarbonyl-2-phenyl-4-benzoyl-3-thiosemicarbazide immediately cyclized to the corresponding thiadiazole at room temperature.

When the alkoxythiocarbonyl-thiosemicarbazides were heated under various conditions hydrogen sulphide was evolved but only traces of the alkoxythiadiazoles were obtained.

The addition of oxidizing agents, such as ferric chloride, iodine, and hydrogen peroxide, is a third method of cyclizing substituted bithioureas. ${ }^{13}, 14$ We found that l-alkoxy-thiocarbonyl-thiosemicarbazides (VI) could be oxidized with hydrogen peroxide to give 2-alkoxy-5-amino-1,3,4-thiadiazoles in good yields.

The 2-alkoxy-5-alkyl(aryl)amino-1,3,4-thiadiazoles were prepared in a somewhat different way. In this case the corresponding alkoxythiocarbonyl hydrazides (VIII) were synthesized as described by Wangel. ${ }^{5}$ These were then allowed to react with alkyl and arylisothiocyanates. The ring closure reaction is analogous to that already described (Scheme 5).

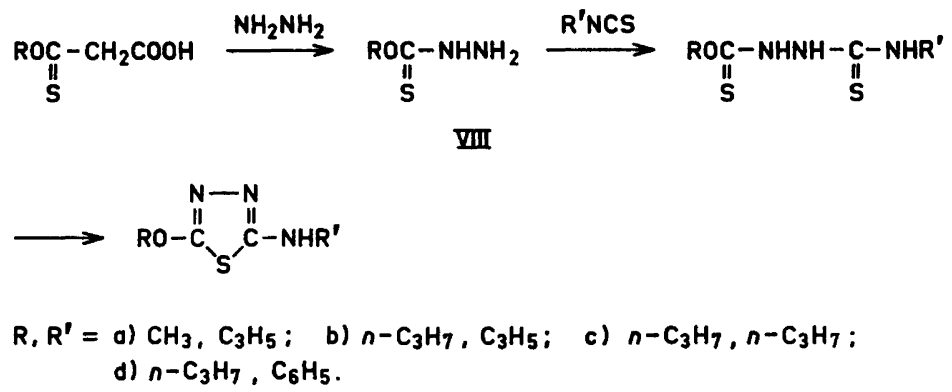

Scheme 5.

The 2-alkoxy-5-amino-1,3,4-thiadiazoles were colourless, crystalline compounds which were stable in cold dilute acid and alkali.

Ring closure of alkoxythiocarbonylthiosemicarbazides (VI) may give both the thiadiazole and triazole derivatives, the presumed thiadiazole structure was verified by hydrolysis reactions and IR-spectra. 
When 2-ethoxy-5-amino-1,3,4-thiadiazole was boiled for $4 \mathrm{~h}$ in $2 \mathrm{~N}$ hydrochloric acid about half of the substance was hydrolyzed and 5-imino-1,3, 4-thiadiazolidine-2-one (IX) was isolated (Scheme 6). When the boiling time was extended to $14 \mathrm{~h}$ all the starting material was hydrolyzed and thiosemicarbazide isolated. Substance (IX), obtained in the first hydrolysis experiment, has also been hydrolyzed. The instability of this compound in acid has been shown by Sugii,4 who could not isolate (IX) when 2-benzoylamino-1,3,4thiadiazole-2-one was hydrolyzed in acid.

By boiling 2-ethoxy-5-amino-1,3,4-thiadiazole in $2 \mathrm{~N}$ sodium hydroxide for $4 \mathrm{~h}$ almost all the substance was hydrolyzed. In this case the thiadiazole ring was broken and 1-ethoxy-thiocarbonyl-semicarbazide $(\mathrm{X})$ was isolated (Scheme 6).

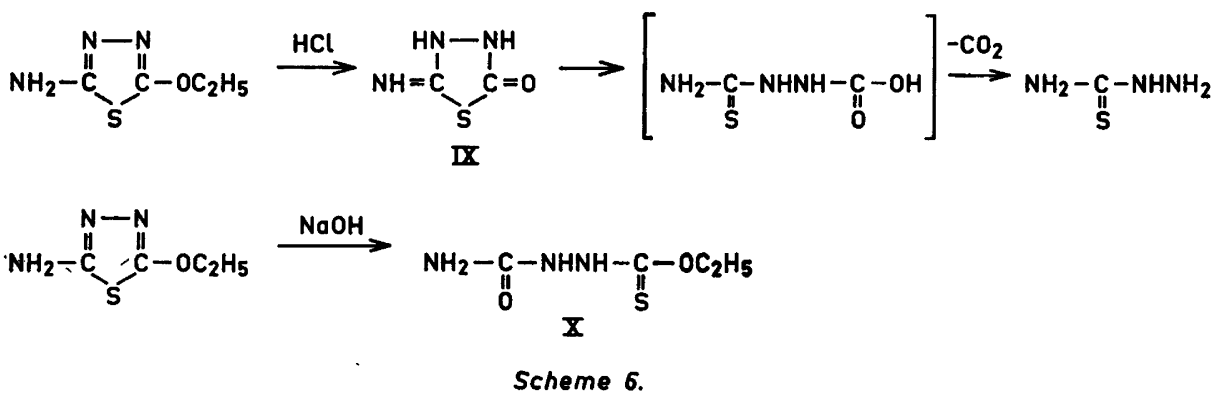

The IR-spectra of 2-amino-5-alkoxy-1,3,4-thiadiazoles in the solid state have an absorption band between $1604-1638 \mathrm{~cm}^{-1}$ corresponding to a primary aminogroup, and an absorption band between $1500-1507 \mathrm{~cm}^{-1}$ corresponding to the $\mathrm{C}=\mathrm{N}$ frequency of the thiadiazole ring. The absorption band of the alkoxy group was found between $1250-1263 \mathrm{~cm}^{-1}$.

The 2-amino-5-alkoxy-1,3,4-thiadiazoles can exist in two tautomeric forms (XI) and (XII).<smiles>[R20]c1nnc(N)s1</smiles>

The IR-spectra showed that in the solid state form (XI), i.e. the amino form, predominated. The substance (IX) obtained by hydrolysis, however, was found to exist in the iminoform in the solid state. The IR spectrum of (IX) had an imino frequency of $1668 \mathrm{~cm}^{-1}$ and a carbonyl frequency of $1697 \mathrm{~cm}^{-1}$.

The amino group in the 2-alkoxy-5-amino-1,3,4-thiadiazoles could be substituted by a chlorine atom using the Sandmeyer procedure. However, the alkoxy group was hydrolyzed at the same time. 2-Ethoxy-5-amino-1,3,4thiadiazole was diazotized in conc. hydrochloric acid at $0-6^{\circ} \mathrm{C}$. By adding cuprous chloride to the diazonium salt, nitrogen was evolved and 5-chloro1,3,4-thiadiazoline-2-one (XIII) was obtained (Scheme 7).

Acta Chem. Scand. 18 (1964) No. 1 


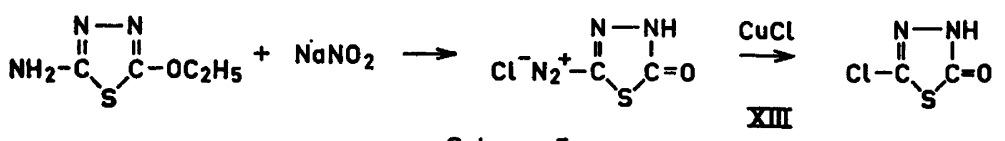

Scheme 7.

Alkylation of the 2-alkoxy-5-amino-1,3,4-thiadiazoles with alkyl halides or alkyl $p$-toluenesulphonates gave the 4-alkyl derivatives (XIV) and not 5-alkylamino derivatives. This is in agreement with the general behaviour of other alkylation reactions of aminothiadiazoles. ${ }^{15}$ Proof of the 4-alkyl configuration was obtained by showing that the imino group could be converted to a carbonyl group (Scheme 8).

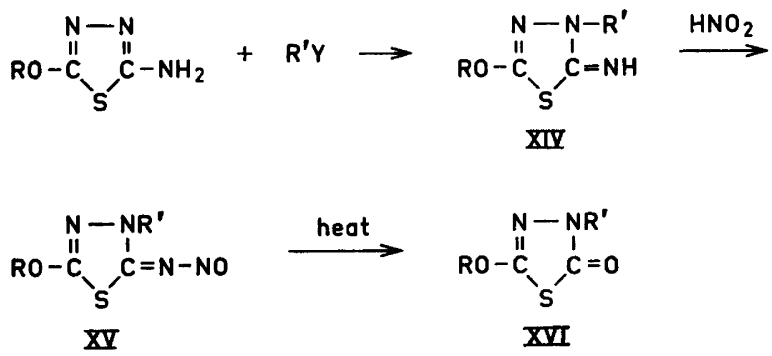

Scheme 8.

The 2-alkoxy-5-amino-1,3,4-thiadiazoles were acylated. The 2-methoxy5-acetylamino-1,3,4-thiadiazole derivative was identical with that obtained from 2-chloro-5-amino-1,3,4-thiadiazole (I) and sodium methoxide (Scheme 2).

\section{EXPERIMENTAL}

2-Phenoxy-5-amino-1,3,4-thiadiazole. $5.8 \mathrm{~g}(0.043 \mathrm{~mole})$ of 2-chloro-5-amino-1,3,4thiadiazole and $5 \mathrm{~g}(0.043 \mathrm{~mole})$ of sodium phenoxide were mixed with $50 \mathrm{~g}$ of phenol. The mixture was warmed on a water-bath for an hour. A dark solution was obtained. After evaporation of the phenol in vacuum, the residue was treated with water. The oil solidified and the mixture was filtered. After repeated recrystallizations from ethanol and boiling with charcoal $1.5 \mathrm{~g}$ of a colourless substance was obtained. M.p. $189-191^{\circ} \mathrm{C}$. (Found: C 49.5; $\mathrm{H}$ 3.7; $\mathrm{N} 2 \mathrm{i} .9 ; \mathrm{S}$ 16.8. Calc. for $\mathrm{C}_{8} \mathrm{H}_{7} \mathrm{~N}_{3} \mathrm{OS}$ (193.2): $\mathrm{C} 49.7 ; \mathrm{H} 3.7 ; \mathrm{N} 21.8$; S 16.6).

2-Methoxy-5-acetylamino-1,3,4-thiadiazole. $2 \mathrm{~g}$ (0.0113 mole) of 2 chloro-5-acetylamino1,3,4-thiadiazole were dissolved in methanol. A solution of an equivalent quantity of sodium methoxide was added. The solution was refluxed for $14 \mathrm{~h}$ after which time no sodium chloride had precipitated. $20 \mathrm{ml}$ of dimethyl sulphoxide were added and the methanol was removed in vacuum. The solution was refluxed for another $3 \mathrm{~h}$ and then evaporated. The residue was treated with water and when the $\mathrm{pH}$, originally $>9$, was adjusted to $\mathrm{pH}=6,0.4 \mathrm{~g}$ of a substance precipitated. M.p. $193-196^{\circ} \mathrm{C}$. On recrystallization from ethanol, $0.3 \mathrm{~g}(21 \%)$ of feltlike crystals were obtained. M.p. $200.5-201.5^{\circ} \mathrm{C}$ (decomp.). (Found: $\mathrm{C} 34.7 ; \mathrm{H} 4.2 ; \mathrm{N} \mathrm{24.3;} \mathrm{S}$ 18.6. Calc. for $\mathrm{C}_{5} \mathrm{H}_{7} \mathrm{~N}_{3} \mathrm{O}_{2} \mathrm{~S}$ (173.2): C 34.7; H 4.1; N 24.3; S 18.5).

Carboxymethyl methylxanthate.$^{9}$ A solution of sodium methoxide was prepared from $46 \mathrm{~g}$ ( 2 moles) of sodium and $500 \mathrm{ml}$ of methanol. $152 \mathrm{~g}$ ( 2 moles) of carbon disulphide were carefully added at a temperature below $40^{\circ} \mathrm{C}$. After stirring for $2.5 \mathrm{~h}$ at room tempera- 
ture, the solution was evaporated to dryness, the yellow residue was dissolved in water. A solution of $189 \mathrm{~g} \mathrm{(2} \mathrm{moles)} \mathrm{of} \mathrm{chloroacetic} \mathrm{acid,} \mathrm{neutralized} \mathrm{with} 140 \mathrm{~g}$ of potassium carbonate in $350 \mathrm{ml}$ of water, was added at $10^{\circ} \mathrm{C}$. The solution was stirred for $2 \mathrm{~h}$ and on acidification with $140 \mathrm{ml}$ of conc. hydrochloric acid an oil separated. The water layer was extracted with ether and the oil and ether extract were combined. The solution was thoroughly washed with water and then dried with sodium sulphate. The ether was evaporated and $270 \mathrm{~g}(81 \%)$ of a yellow oil remained. The oil resisted all attempts at crystallisation. The equivalent weight was determined by titration to 166 (calc. 166).

1-Methoxythiocarbonyl-3-thiosemicarbazide. $270 \mathrm{~g}$ (1.63 moles) of carboxymethyl methylxanthate were neutralized with $325 \mathrm{ml}$ of $5 \mathrm{~N}$ sodium hydroxide under cooling. $155 \mathrm{~g}$ (1.7 moles) of thiosemicarbazide were added and then a further $325 \mathrm{ml}$ of $5 \mathrm{~N}$ sodium hydroxide. The mixture was stirred for $14 \mathrm{~h}$ and then the solution was treated with charcoal and acidified with $250 \mathrm{ml}$ of conc. acetic acid. A colourless substance precipitated, which was purified by dissolving in $1 \mathbf{N}$ sodium hydroxide and then precipitating with acid. $152 \mathrm{~g} \mathrm{(56 \% )}$ were obtained. M.p. $132.5-133.5^{\circ} \mathrm{C}$ (decomp.). (Found: C 21.7; H 4.2; $\mathrm{N} 25.4 ; \mathrm{O} 9.6 ; \mathrm{S} 39.1$. Calc. for $\mathrm{C}_{3} \mathrm{H}_{7} \mathrm{~N}_{3} \mathrm{O} \mathrm{S}_{2}(165.2)$ : $\left.\mathrm{C} 21.8 ; \mathrm{H} 4.3 ; \mathrm{N} 25.4 ; \mathrm{O} 9.7 ; \mathrm{S} \mathrm{38.8}\right)$.

2-Methoxy-5-amino-1,3,4-thiadiazole. $60 \mathrm{~g}(0.364 \mathrm{~mole})$ of 1-methoxythiocarbonyl-3thiosemicarbazide were added to $250 \mathrm{ml}$ of water. The mixture was chilled to $+1^{\circ} \mathrm{C}$ in an ice-bath. $600 \mathrm{ml}$ of $3 \%$ hydrogen peroxide were slowly added at that temperature. Sulphur precipitated. After the completed addition, the temperature slowly rose to $20^{\circ} \mathrm{C}$. The mixture was stirred for $3 \mathrm{~h}$, and then filtered. $44 \mathrm{~g}$ of a yellow substance were obtained, which was then boiled with $500 \mathrm{ml}$ of water. $11.4 \mathrm{~g}$ of sulphur were separated. The solution was boiled with charcoal and then chilled. $24.7 \mathrm{~g} \mathrm{(52} \%)$ of a white substance crystallized. M.p. $158-159^{\circ} \mathrm{C}$. By evaporation of the water solution, another $4 \mathrm{~g}$ of the substance were obtained. Recrystallization from water did not raise the melting-point. Total yield $60 \%$. (Found: C 27.5; $\mathrm{H} 4.1 ; \mathrm{N} 32.2 ; \mathrm{S}$ 24.3. Calc. for $\mathrm{C}_{3} \mathrm{H}_{5} \mathrm{~N}_{3} \mathrm{OS}$ (131.2): C 27.5; $\mathrm{H} 3.8 ; \mathrm{N} 32.0$; S 24.5).

Carboxymethyl ethylxanthate. ${ }^{9}$ Carboxymethyl ethylxanthate was prepared in the same manner as carboxymethyl methylxanthate. $189 \mathrm{~g}$ (2 moles) of chloroacetic acid were neutralized. To this solution, $320.6 \mathrm{~g}(2 \mathrm{moles})$ of the potassium salt of ethylxanthic acid were added. The solution was stirred for $2 \mathrm{~h}$ and then neutralized. $300 \mathrm{~g}$ of a yellow oil precipitated which crystallized on seeding. The substance was washed with petroleum ether. The yield was $290 \mathrm{~g}(81 \%)$. M.p. $55-59^{\circ} \mathrm{C}$.

1-Ethoxythiocarbonyl-3-thiosemicarbazide. $284 \mathrm{~g}$ (1.57 moles) of carboxymethyl ethylxanthate were neutralized with sodium hydroxide. To this solution $143 \mathrm{~g}$ ( $1.57 \mathrm{moles})$ of thiosemicarbazide and $300 \mathrm{ml}$ of $5 \mathrm{~N}$ sodium hydroxide were added. The procedure was analogous to that for 1-methoxythiocarbonyl-3-thiosemicarbazide. The mixture was stirred for $20 \mathrm{~h}$ and then neutralized. A colourless substance precipitated. On recrystallization from water $225 \mathrm{~g}(80 \%)$ were obtained. M.p. $157-161^{\circ} \mathrm{C}$ (decomp.). (Found: C 26.5; $\mathrm{H}$ 5.3; $\mathrm{N} 23.5 ; \mathrm{S} \mathrm{35.7}$. Calc. for $\mathrm{C}_{4} \mathrm{H}_{9} \mathrm{~N}_{3} \mathrm{OS}_{2}(179.3)$ : C 26.8; $\mathrm{H} 5.1 ; \mathrm{N} 23.5 ; \mathrm{S} \mathrm{35.7)}$.

2-Ethoxy-5-amino-1,3,4-thiadiazole. $179.3 \mathrm{~g}$ (1 mole) of 1-ethoxythiocarbonyl-3-thiosemicarbazide were added to $500 \mathrm{ml}$ of water. $897 \mathrm{ml}$ of $6 \%$ hydrogen peroxide were added dropwise at $0-4^{\circ} \mathrm{C}$ during $2 \mathrm{~h}$ after which time the ice bath was removed. The temperature rose to $37^{\circ} \mathrm{C}$. After $3 \mathrm{~h}$ the mixture was filtered and $168 \mathrm{~g}$ of a yellow substance were obtained. This was boiled with $10 \mathrm{l}$ of water and $40 \mathrm{~g}$ of sulphur were separated. On cooling $110 \mathrm{~g}(76 \%)$ of colourless crystals were obtained. M.p. $182.5-185^{\circ} \mathrm{C}$. (Found: C 33.1; $\mathrm{H} 4.9$; $\mathrm{N} 28.8 ; \mathrm{S} 22.2$. Calc. for $\mathrm{C}_{4} \mathrm{H}_{7} \mathrm{~N}_{3} \mathrm{OS}(145.2)$ : C 33.1; $\mathrm{H} \mathrm{4.9;} \mathrm{N} 28.9$; S 22.1).

Carboxymethyl propylxanthate. The procedure was the same as for carboxymethyl methylxanthate. 1 mole of the sodium salt of propylxanthic acid was prepared. This salt was then added to 1 mole of neutralized chloroacetic acid. After $2 \mathrm{~h}$ the solution was acidified and $195 \mathrm{~g}$ of an oil was obtained which crystallized on scratching. After repeated recrystallizations from ligroin, $168 \mathrm{~g}(87 \%)$ of a slight yellow substance were obtained. M.p. 39- $42^{\circ} \mathrm{C}$. (Found: C 37.2; $\mathrm{H} \mathrm{5.4;} \mathrm{S} 32.4$. Calc. for $\mathrm{C}_{8} \mathrm{H}_{10} \mathrm{O}_{8} \mathrm{~S}_{2}(194.3): \mathrm{C} 37.1 ; \mathrm{H} \mathrm{5.2}$; S 33.0).

1.Propoxythiocarbonyl-3-thiosemicarbazide. $50.5 \mathrm{~g}(0.26 \mathrm{~mole})$ of carboxymethyl propylxanthate were neutralized. To this solution $24 \mathrm{~g}(0.26 \mathrm{~mole})$ of thiosemicarbazide and $130 \mathrm{ml}$ of $2 \mathrm{~N}$ sodium hydroxide were added. The procedure was the same as for 1-methoxythiocarbonyl-3-thiosemicarbazide. $52 \mathrm{~g}$ of a white substance precipitated on acidifi- 
cation. On recrystallization from water $40 \mathrm{~g}(80 \%)$ of the substance were obtained. M.p. $140-142^{\circ} \mathrm{C}$. (Found: $\mathrm{C} \mathrm{31.3;} \mathrm{H} \mathrm{6.0;} \mathrm{N} \mathrm{21.8;} \mathrm{S} 32.6$. Calc. for $\mathrm{C}_{5} \mathrm{H}_{11} \mathrm{~N}_{3} \mathrm{OS}_{2}$ (193.3): $\mathrm{C} 31.1$; H 5.7; N 21.7; S 33.2).

2-Propoxy-5-amino-1,3,4-thiadiazole. $30 \mathrm{~g}$ (0.16 mole) of 1-propoxythiocarbonyl-3thiosemicarbazide were added to $450 \mathrm{ml}$ of water. The mixture was cooled to $10^{\circ} \mathrm{C} .300 \mathrm{ml}$ of $3 \%$ hydrogen peroxide were added during $30 \mathrm{~min}$ after which the ice bath was removed. The reaction mixture was stirred for $6 \mathrm{~h}$. On filtration $26.5 \mathrm{~g}$ of a yellow substance was obtained. By boiling with water, $4.7 \mathrm{~g}$ of sulphur were separated. $20.5 \mathrm{~g}$ of a white substance precipitated on cooling. M.p. $175-176.5^{\circ} \mathrm{C}$. (Found: C 37.6; H 5.6; N 26.4; O 10.0; S 20.1. Calc. for $\mathrm{C}_{6} \mathrm{H}_{9} \mathrm{~N}_{3} \mathrm{OS}$ (159.2): $\mathrm{C} 37.7 ; \mathrm{H} 5.7 ; \mathrm{N} 26.4 ; \mathrm{O} 10.1 ; \mathrm{S} 20.1$ ).

Carboxymethyl isopropylxanthate. 1 mole of the sodium salt of isopropylxanthic acid was prepared as described above for carboxymethyl methylxanthate. To this 1 mole of neutralized chloroacetic acid was added. After $2 \mathrm{~h}$ the solution was acidified. $154.2 \mathrm{~g}$ of a yellow oil were obtained which crystallized on scratching. The crystals were washed with petroleum ether and $125 \mathrm{~g}(65 \%)$ remained after washing. M.p. $34-45^{\circ} \mathrm{C}$. On recrystallization from ether-petroleum ether, the melting point was raised to $40-43^{\circ} \mathrm{C}$. (Found: C 37.3; H 5.3; S 33.0. Calc. for $\mathrm{C}_{6} \mathrm{H}_{10} \mathrm{O}_{3} \mathrm{~S}_{2}(194.3)$; C 37.1; H 5.2; S 33.0).

1-Isopropoxythiocarbonyl-3-thiosemicarbazide. $113 \mathrm{~g}(0.58 \mathrm{~mole})$ of carboxymethyl isopropylxanthate were neutralized. To this solution were added $53 \mathrm{~g}(0.58 \mathrm{~mole})$ of thiosemicarbazide and $116 \mathrm{ml}$ of $5 \mathrm{~N}$ sodium hydroxide. After stirring for $19 \mathrm{~h}$, the solution was acidified and $81 \mathrm{~g}$ of colourless crystals precipitated; m.p. $158-160^{\circ} \mathrm{C}$ (decomp.). On recrystallization from water $79 \mathrm{~g}(70 \%)$ were obtained; m.p. $164-167^{\circ} \mathrm{C}$ (decomp.). (Found: C 31.1; H 5.8; N 22.0: O 8.6; $\mathrm{S}$ 33.1. Calc. for $\mathrm{C}_{6} \mathrm{H}_{11} \mathrm{~N}_{3} \mathrm{OS}_{2}$ (193.3): C 31.1; $\mathrm{H}$ 5.7; $\mathrm{N} 21.7 ; \mathrm{O} 8.3 ; \mathrm{S} 33.2)$.

2-Isopropoxy-5-amino-1,3,4-thiadiazole. $66 \mathrm{~g}(0.342 \mathrm{~mole})$ of 1-isopropoxythiocarbony]3-thiosemicarbazide were suspended in $300 \mathrm{ml}$ of water. The mixture was cooled to $+5^{\circ} \mathrm{C}$ and $400 \mathrm{ml}$ of $4 \%$ hydrogen peroxide were added. The ice-bath was removed and the reaction mixture was stirred for $6 \mathrm{~h}$. The yellow precipitate was boiled with water and sulphur was separated. On chilling, a substance precipitated which was recrystallized from water. $27 \mathrm{~g}(52 \%)$ of colourless crystals were obtained. M.p. 173.5 - 175 ${ }^{\circ} \mathrm{C}$. (Found: C 37.6; $\mathrm{H} \mathrm{5.9;} \mathrm{N} 26.4 ; \mathrm{O} 10.0 ; \mathrm{S} 20.1$. Calc. for $\mathrm{C}_{5} \mathrm{H}_{9} \mathrm{~N}_{3} \mathrm{OS}(159.2)$ : C 37.7; $\mathrm{H}$ 5.7; $\mathrm{N} 26.4$; O 10.1; S 20.1).

Carboxymethyl butylxanthate. The procedure was analogous to that for carboxymethyl methylxanthate. 1 mole of the sodium salt of butylxanthic acid was prepared and dissolved in $150 \mathrm{ml}$ of water. Neutralized chloroacetic acid was added to the solution. After $2 \mathrm{~h}$ the solution was acidified. $158 \mathrm{~g}$ of a pale brown oil precipitated. The oil did not crystallize, and was used without further purification in the next synthesis.

Butoxythiocarbonyl-3-thiosemicarbazide. $104 \mathrm{~g}(0.5 \mathrm{~mole})$ of carboxymethyl butylxanthate were neutralized with $2 \mathrm{~N}$ sodium hydroxide. To the solution, $45.5 \mathrm{~g}(0.5 \mathrm{~mole})$ of thiosemicarbazide and $250 \mathrm{ml}$ of $2 \mathrm{~N}$ sodium hydroxide were added. The mixture was stirred for $18 \mathrm{~h}$, heated with charcoal and then acidified. $88.8 \mathrm{~g} \mathrm{(86 \% )}$ of slight yellow crystals were obtained. M.p. $121-125^{\circ} \mathrm{C}$. After repeated recrystallizations from water the m.p. was unchanged. (Found: $\mathrm{C} \mathrm{34.9;} \mathrm{H} 6.6 ; \mathrm{N} 20.0 ; \mathrm{S} \mathrm{30.4}$. Calc. for $\mathrm{C}_{6} \mathrm{H}_{13} \mathrm{~N}_{3} \mathrm{OS}_{2}$ (207.3): C 34.8; H 6.3; N 20.3; S 30.9).

2-Butoxy-5-amino-1,3,4-thiadiazole. $50 \mathrm{~g}(0.24$ mole $)$ of butoxythiocarbonyl-3-thiosemicarbazide were added to $200 \mathrm{ml}$ of water. $500 \mathrm{ml}$ of $3 \%$ hydrogen peroxide were added dropwise to the mixture. The temperature was kept below $30^{\circ} \mathrm{C}$. After $3 \mathrm{~h}$ the mixture was filtered and $\mathbf{4 3} \mathrm{g}$ of a yellow substance were obtained. This was boiled with a mixture of 1.51 of water and $500 \mathrm{ml}$ of $95 \%$ ethanol, $7.2 \mathrm{~g}$ of sulphur were separated. On cooling, $33.5 \mathrm{~g}(80 \%)$ of a colourless product were obtained. M.p. $149-150.5^{\circ} \mathrm{C}$. (Found: C 42.0; $\mathrm{H}$ 6.6; $\mathrm{N} 24.2 ; \mathrm{S}$ 18.5. Calc. for $\mathrm{C}_{6} \mathrm{H}_{11} \mathrm{~N}_{3} \mathrm{OS}$ (173.2): $\mathrm{C} 41.6 ; \mathrm{H} 6.4 ; \mathrm{N} \mathrm{24.3;} \mathrm{S} \mathrm{18.5).}$

Methoxythiocarbonylhydrazine. $84 \mathrm{~g}(0.5$ mole) of carboxymethyl methylxanthate were neutralized with $250 \mathrm{ml}$ of $2 \mathrm{~N}$ sodium hydroxide. The solution was cooled to $0^{\circ} \mathrm{C}$ in an ice-bath. $2.9 \mathrm{ml}(0.58 \mathrm{~mole})$ of hydrazine hydrate were added to the solution at $0-45^{\circ} \mathrm{C}$. After 20 min a colourless substance precipitated. The reaction mixture was placed in a refrigerator overnight and filtered. The product obtained was recrystallized from ethanol to give $34 \mathrm{~g}(64 \%)$ of a colourless substance. M.p. $72-74^{\circ} \mathrm{C}$. (Found: C 22.7; H 5.9; $\mathrm{N} 26.5 ; \mathrm{S} 30.6$. Calc. for $\mathrm{C}_{2} \mathrm{H}_{6} \mathrm{~N}_{2} \mathrm{OS}(106.2)$ : C 22.6; H 5.7; $\mathrm{N} \mathrm{26.4;} \mathrm{S} \mathrm{30.2)}$.

1-Methoxythiocarbonyl-4-allyl-3-thiosemicarbazide. $20 \mathrm{~g}(0.188 \mathrm{~mole})$ of methoxythiocarbonylhydrazine were added to $100 \mathrm{ml}$ of $95 \%$ ethanol. $18.6 \mathrm{~g}(0.188 \mathrm{~mole})$ of allyl 
isothiocyanate were added to the mixture. After $15 \mathrm{~min}$ there was complete solution. The solution was warmed to $40^{\circ} \mathrm{C}$ and a substance precipitated which was filtered after $45 \mathrm{~min}$. Yield $24 \mathrm{~g}$; m.p. $128-131.5^{\circ} \mathrm{C}$ (decomp.). On evaporation of the mother liquor, a second crop of $8.5 \mathrm{~g}$ of the substance precipitated. M.p. $129-132^{\circ} \mathrm{C}$ (decomp.). After recrystallization from ethanol, $30.5 \mathrm{~g} \mathrm{(79 \% )}$ of a colourless substance were obtained; m.p. $132-134^{\circ} \mathrm{C}$ (decomp.). (Found: $\mathrm{C} 35.1 ; \mathrm{H} 5.6 ; \mathrm{N} 20.6$; S 31.3. Calc. for $\mathrm{C}_{6} \mathrm{H}_{11} \mathrm{~N}_{3} \mathrm{OS}_{2}$ (205.3): C 35.1; H 5.4; N 20.5; S 31.2).

2-Methoxy-5-allylamino-1,3,4-thiadiazole. $5 \mathrm{~g}$ (0.0244 mole) of 1-methoxythiocarbonyl4-allyl-3-thiosemicarbazide were added to $70 \mathrm{ml}$ of water. $50 \mathrm{ml}$ of $3 \%$ hydrogen peroxide were added to the mixture and sulphur precipitated. The reaction mixture was stirred for $1 \mathrm{~h}$ at room temperature and then warmed for $10 \mathrm{~min}$ on a water-bath. Parts of the undissolved product dissolved and the sulphur clotted. The mixture was filtered and $1.15 \mathrm{~g}$ of a yellow substance separated. On cooling the mother liquor, $1.55 \mathrm{~g}$ of colourless needles crystallized. On evaporation of the mother liquor to a total volume of $70 \mathrm{ml}, \mathrm{a}$

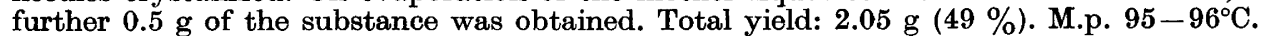
(Found: $\mathrm{C} 41.9 ; \mathrm{H}$ 5.4; $\mathrm{N} 24.5 ; \mathrm{S}$ 18.8. Calc. for $\mathrm{C}_{6} \mathrm{H}_{9} \mathrm{~N}_{3} \mathrm{OS}$ (171.2): $\mathrm{C} 42.1 ; \mathrm{H} 5.3 ; \mathrm{N} 24.5$; S 18.7).

Propoxythiocarbonylhydrazine. $200 \mathrm{~g}$ (1.03 moles) of carboxylmethyl propylxanthate were neutralized with $5 \mathrm{~N}$ sodium hydroxide at $10^{\circ} \mathrm{C}$. The solution was cooled to $0^{\circ} \mathrm{C}$ and $50 \mathrm{ml}$ of hydrazine hydrate were added. The solution was stirred for $3 \mathrm{~h}$ and an oil precipitated. The oil was separated and the mother liquor extracted with ether. The oil and the ether extracts were combined and dried with sodium sulphate. The ether was evaporated and $100 \mathrm{~g}$ of a red oil remained. This oil was used in next synthesis without further purification.

1-Propoxythiocarbonyl-4-allyl-3-thiosemicarbazide. $15 \mathrm{~g}(0.112$ mole) of propoxythiocarbonylhydrazine were dissolved in $75 \mathrm{ml}$ of ethanol. An ethanol solution of allyl isothiocyanate was added to the above solution. The solution was refluxed for $3 \mathrm{~h}$. On cooling and addition of water, a substance precipitated, $20 \mathrm{~g}$ of slightly orange crystals were obtained; m.p. $95-105^{\circ} \mathrm{C}$. The substance was purified by recrystallization from ethanolwater and by reprecipitation from sodium hydroxide with hydrochloric acid. $13 \mathrm{~g} \mathrm{(50 \% )}$ of colourless crystals were obtained; m.p. $114-115^{\circ} \mathrm{C}$. (Found: $\mathrm{C} 41.2 ; \mathrm{H} 6.7 ; \mathrm{N} 18.2$; $\mathrm{S}$ 27.8. Calc. for $\mathrm{C}_{8} \mathrm{H}_{15} \mathrm{~N}_{3} \mathrm{OS}_{2}$ (233.3): $\mathrm{C} 41.2 ; \mathrm{H}$ 6.5; $\mathrm{N} 18.0 ; \mathrm{S} 27.5$ ).

2-Propoxy-5-allylamino-1,3,4-thiadiazole. $12.7 \mathrm{~g}(0.054 \mathrm{~mole})$ of 1 -propoxythiocarbonyl4-allyl-3-thiosemicarbazide were added to $50 \mathrm{ml}$ of water. $127 \mathrm{ml}$ of $3 \%$ hydrogen peroxide were added to the mixture at room temperature. The reaction mixture was stirred overnight and then filtered. The yellow substance obtained was treated with cold ethanol. $1.4 \mathrm{~g}$ of sulphur remained undissolved and were separated. The ethanol solution was evaporated to a volume of $50 \mathrm{ml}$ and water was added to the solution. On cooling, $5.3 \mathrm{~g}$ $(49 \%)$ of a colourless substance were obtained; m.p. $70-72^{\circ} \mathrm{C}$. After recrystallization from ethanol-water $4.7 \mathrm{~g}$ of colourless crystals were obtained. M.p. $72-7^{\circ} \mathrm{C}$. (Found: C 48.1; H 6.6; N 21.3; S 16.4. Calc. for $\mathrm{C}_{8} \mathrm{H}_{13} \mathrm{~N}_{3} \mathrm{OS}(199.3)$ : C 48.2; H 6.6; N 21.1; S 16.1).

1-Propoxythiocarbonyl-4-n-propyl-3-thiosemicarbazide. $12.7 \mathrm{~g}(0.065 \mathrm{~mole})$ of carboxymethyl propylxanthate were neutralized with $2 \mathrm{~N}$ sodium hydroxide. $8.7 \mathrm{~g}(0.065$ mole) of 4-propyl-3-thiosemicarbazide and $32.5 \mathrm{ml}$ of $2 \mathrm{~N}$ sodium hydroxide were added to the above solution. The mixture was stirred for $22 \mathrm{~h}$. The solution obtained was neutralized and $14 \mathrm{~g}$ of a colourless substance precipitated. M.p. $93-111^{\circ} \mathrm{C}$. After recrystallization from ethanol-water, $11.5 \mathrm{~g}(75 \%)$ of colourless needles were obtained; m.p. $120-123^{\circ} \mathrm{C}$. (Found: C 40.8; $\mathrm{H} 7.3 ; \mathrm{N} 18.0 ; \mathrm{S} 27.2$. Calc. for $\mathrm{C}_{8} \mathrm{H}_{17} \mathrm{~N}_{3} \mathrm{OS}_{2}(235.4)$ : $\mathrm{C} 40.8 ; \mathrm{H} 7.3 ; \mathrm{N} 17.9$; S 27.2).

2-Propoxy-5-propylamino-1,3,4-thiadiazole. $3 \mathrm{~g}(0.0127$ mole) of 1-propoxythiocarbonyl4-propyl-3-thiosemicarbazide were suspended in $40 \mathrm{ml}$ of water. $30 \mathrm{ml}$ of $3 \%$ hydrogen peroxide were added. The reaction mixture was heated at $60^{\circ} \mathrm{C}$ for $1.5 \mathrm{~h}$. On filtration $2.1 \mathrm{~g}$ of a green-yellow substance was obtained. The latter was heated with acetone, the sulphur was removed and the acetone solution evaporated. The residue was recrystallized twice from ligroin to give $1.4 \mathrm{~g}(55 \%)$ of a colourless substance; m.p. $77-79^{\circ} \mathrm{C}$. (Found: C 47.4; $\mathrm{H} 7.5 ; \mathrm{N} 20.8$; S 15.8. Calc. for $\mathrm{C}_{8} \mathrm{H}_{15} \mathrm{~N}_{3} \mathrm{OS}(201.3)$ : C 47.7; H 7.5; $\left.\mathrm{N} 20.9 ; \mathrm{S} 15.9\right)$.

1-propoxythiocarbonyl-4-phenyl-3-thiosemicarbazide. $25 \mathrm{~g}(0.186 \mathrm{~mole})$ of propoxy. thiocarbonylhydrazide were dissolved in $170 \mathrm{ml}$ of $95 \%$ ethanol. $25.5 \mathrm{~g}(0.186 \mathrm{~mole})$ of phenyl isothiocyanate were added to the solution. No temperature rise could be noticed. The solution was warmed for $15 \mathrm{~min}$. A substance precipitated and hydrogensulphide

Acta Chem. Scand. 18 (1964) No. 1 
was evolved. The heating was interrupted and the reaction mixture stirred for another $1.5 \mathrm{~h}$ and then filtered. $39 \mathrm{~g}(78 \%)$ of a colourless substance were obtained; m.p. $148-150.5^{\circ} \mathrm{C}$ (decomp.). The substance was recrystallized from ethanol but the m.p. did not rise. (Found: $\mathrm{C} 49.1 ; \mathrm{H} \mathrm{5.4;} \mathrm{N}$ 15.7; $\mathrm{S}$ 23.8. Calc. for $\mathrm{C}_{11} \mathrm{H}_{15} \mathrm{~N}_{3} \mathrm{OS}_{2}(269.4$ ): $\mathrm{C} 49.1$; H 5.6; N 15.6; $\mathrm{S} 23.8$ ).

2.Propoxy-5-anilino-1,3,4-thiadiazole. $15 \mathrm{~g}(0.056 \mathrm{~mole})$ of 1-propoxythiocarbonyl4-phenyl-3-thiosemicarbazide were added to $100 \mathrm{ml}$ of water. $150 \mathrm{ml}$ of $3 \%$ hydrogen peroxide were added to the mixture. The reaction mixture was warmed at $45^{\circ} \mathrm{C}$ for $1.5 \mathrm{~h}$. On cooling, the mixture was filtered and $14 \mathrm{~g}$ of a yellow substance were obtained. By boiling this substance with ethanol, sulphur was separated and $11.6 \mathrm{~g}$ of the desired substance precipitated on cooling. After recrystallization from ethanol, $9.0 \mathrm{~g} \mathrm{(68 \% )} \mathrm{of}$ colourless crystals were obtained. M.p. $115-116.5^{\circ} \mathrm{C}$. (Found: C 56.3; H 5.7; N 18.0; S. 13.2. Calc. for $\mathrm{C}_{11} \mathrm{H}_{13} \mathrm{~N}_{3} \mathrm{OS}(235.3)$ : $\left.\mathrm{C} 56.2 ; \mathrm{H} 5.6 ; \mathrm{N} 17.9 ; \mathrm{S} 13.6\right)$.

Acid hydrolysis of 2-ethoxy-5-amino-1,3,4-thiadiazole. $10 \mathrm{~g}(0.69 \mathrm{~mole})$ of 2-ethoxy5-amino-1,3,4-thiadiazole were boiled in $50 \mathrm{ml}$ of $2 \mathrm{~N}$ hydrochloric acid for $4 \mathrm{~h}$. The solution was cooled and neutralized. $7.9 \mathrm{~g}$ of a colourless substance precipitated. This

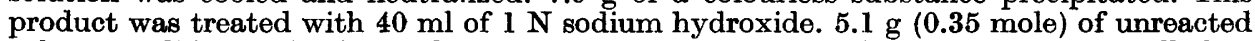
substance did not dissolve and were separated. On neutralizing and cooling the alkaline solution, $1.7 \mathrm{~g}(43 \%)$ of 5 -imino-1,3,4-thiadiazole-2-one precipitated; m.p. $170-174^{\circ} \mathrm{C}$ (decomp.) (lit. ${ }^{17} 177^{\circ} \mathrm{C}$ (decomp.)). Evaporation of this solution and the mother liquor gave a further $1 \mathrm{~g}$. Total yield: $2.7 \mathrm{~g}(68 \%)$. The substance gave no melting point depression with the substance described by Shoichi Ban ${ }^{17}$ and has the same IR-spectrum as this substance.

In a second experiment, $2 \mathrm{~g}$ of 2-ethoxy-5-amino-1,3,4-thiadiazole were boiled in $15 \mathrm{ml}$ of $2 \mathrm{~N}$ hydrochloric acid for $14 \mathrm{~h}$. On neutralizing, no substance precipitated. The solution was evaporated and $0.4 \mathrm{~g}$ precipitated. This substance consisted for the main part of thiosemicarbazide. The substance was identified by its IR-spectrum and gave no melting point depression with thiosemicarbazide.

Alkaline hydrolysis of 2-ethoxy-5-amino-1,3,4-thiadiazole. $10 \mathrm{~g}(0.69 \mathrm{~mole})$ of 2-ethoxy5 -amino-1,3,4-thiadiazole were boiled in a mixture of $50 \mathrm{ml}$ of $2 \mathrm{~N}$ sodium hydroxide and $50 \mathrm{ml}$ of ethanol for $4 \mathrm{~h}$. The ethanol was evaporated and $0.5 \mathrm{~g}$ of the starting material could be separated. The solution was neutralized and $8.1 \mathrm{~g}$ of 1-ethoxythiocarbonyl. semicarbazide precipitated; m.p. $162-163^{\circ}$ C. (Found: C 29.3; H 5.5; N 25.2; S 19.6. Calc. for $\mathrm{C}_{4} \mathrm{H}_{9} \mathrm{~N}_{3} \mathrm{O}_{2} \mathrm{~S}$ (163.2): $\mathrm{C} 29.4 ; \mathrm{H} 5.6 ; \mathrm{N} 25.8 ; \mathrm{S} 19.7$ ). 1-Ethoxythiocarbonyl-semicarbazide was also prepared from carboxymethyl ethylxanthate and semicarbazide as described by Guha and Dutta. ${ }^{18}$ The two substances obtained in different ways were identical.

Diazotization of 2-ethoxy-5-amino-1,3,4-thiadiazole. $10 \mathrm{~g}(0.076 \mathrm{~mole})$ of 2 ethoxy-5amino-1,3,4-thiadiazole were dissolved in $75 \mathrm{ml}$ of conc. hydrochloric acid. The solution was cooled to $0^{\circ} \mathrm{C}$ and $5.8 \mathrm{~g}(0.084$ mole) of sodium nitrite, dissolved in $20 \mathrm{ml}$ of water, were added to the above solution at $0^{\circ}-5^{\circ} \mathrm{C}$. A yellow substance precipitated. When the addition was complete the temperature was allowed to rise and $7.5 \mathrm{~g}(0.076 \mathrm{~mole})$ of cuprous chloride dissolved in a mixture of $50 \mathrm{ml}$ of water and $50 \mathrm{ml}$ of conc. hydrochloric acid were added. A violent gas evolution occurred and the reaction mixture darkened. The reaction mixture was stirred for $14 \mathrm{~h}$ at room temperature and $1.8 \mathrm{~g}$ of 5-chloro-1,3,4thiadiazoline-2-one precipitated; m.p. $103-106^{\circ} \mathrm{C}$. The mother liquor was shaken with ether. The ether solution was dried and evaporated and a further $6.9 \mathrm{~g}$ were obtained. The substance was recrystallized from ligroin and $6.5 \mathrm{~g}(63 \%)$ were obtained; m.p. $105-107^{\circ} \mathrm{C}$ (lit. ${ }^{16} 107^{\circ} \mathrm{C}$ ). (Found: $\mathrm{C} 17.6 ; \mathrm{H} 0.7 ; \mathrm{Cl} 25.8 ; \mathrm{N}$ 21.0; $\mathrm{S}$ 23.3. Calc. for $\mathrm{C}_{2} \mathrm{HClN}_{2} \mathrm{OS}(136.6)$ C 17.6; H 0.7; Cl 26.0; N 20.5; S 23.5).

2-Propoxy-4-benzyl-5-imino-1,3,4-thiadiazolinium hydrobromide. $5.1 \mathrm{~g}$ (0.032 mole) of 2-propoxy-5-amino-1,3,4-thiadiazole and $5.5 \mathrm{~g}(0.032 \mathrm{~mole})$ of $\alpha$-bromotoluene were mixed and heated at $100^{\circ} \mathrm{C}$ for $1 \mathrm{~h}$. A homogeneous phase was obtained. A gas was evolved. The oil was cooled and washed with ether to remove unreacted $a$-bromotoluene. The undissolved oil was treated with acetone and a solid substance precipitated. On recrystallization from chloroform - ether, $1.2 \mathrm{~g}(11 \%)$ of a colourless substance were obtained; m.p. $146-147^{\circ} \mathrm{C}$ (decomp.). The acetone solution was evaporated but the residue was a mixture of several substances and was not further purified. (Found: $\mathrm{C} \mathrm{43.4;} \mathrm{H} 5.1 ; \mathrm{Br} 24.3$; $\mathrm{N}$ 12.7; $\mathrm{S}$ 9.7. Calc. for $\mathrm{C}_{12} \mathrm{H}_{16} \mathrm{BrN}_{3} \mathrm{OS}$ (330.3): C 43.6; $\mathrm{H} 4.9 ; \mathrm{Br} 24.2$; $\mathrm{N} 12.7$; $\mathrm{S} 9.7$ ). 
2-Ethoxy-4-methyl-5-imino-1,3,4-thiadiazoline. $5 \mathrm{~g}(0.0344 \mathrm{~mole})$ of 2-ethoxy-5-amino1,3,4-thiadiazole and $7.9 \mathrm{~g}(0.0413 \mathrm{~mole})$ of methyl $p$-toluenesulphonate were mixed and heated in a water-bath at $80^{\circ} \mathrm{C}$ for $45 \mathrm{~min}$. After cooling, the melt was washed with ether. By seeding the melt crystallized. The crude product was recrystallized from acetone and $8.25 \mathrm{~g}(72 \%)$ of 2-ethoxy-4-methyl-5-imino-1,3,4-thiadiazolinium $p$-toluenesulphonate were obtained; m.p. $113-114^{\circ} \mathrm{C}$. (Found: $\mathrm{C} 43.4 ; \mathrm{H}$ 5.0; $\mathrm{N} 12.6 ; \mathrm{S}$ 19.3. Calc. for $\mathrm{C}_{12} \mathrm{H}_{17} \mathrm{~N}_{3} \mathrm{O}_{4} \mathrm{~S}_{2}$ (331.4): $\mathrm{C} 43.5 ; \mathrm{H}$ 5.2; $\left.\mathrm{N} 12.7 ; \mathrm{S} 19.4\right)$.

The hydrochloric salt was prepared by dissolving 2-ethoxy-4-methyl-5-imino-1,3,4thiadiazolinium $p$-toluenesulphonate in $1 \mathrm{~N}$ sodium hydroxide. The solution was extracted with ethyl acetate. The ethyl acetate layer was dried and evaporated. The residue was treated with ethanolic hydrochloric acid, and 2-ethoxy-4-methyl-5-imino-1,3,4-thiadiazolinium hydrochloride precipitated. The product was recrystallized from acetone. M.p. $137-138^{\circ} \mathrm{C}$ (decomp.). (Found: $\mathrm{C} \mathrm{30.7;} \mathrm{H}$ 5.2; $\mathrm{Cl} 17.7 ; \mathrm{N} 21.7 ; \mathrm{S}$ 16.2. Calc. for $\mathrm{C}_{5} \mathrm{H}_{10} \mathrm{ClN}_{3} \mathrm{OS}(195.7)$ : C 30.7; H 5.2; $\left.\mathrm{Cl} 18.1 ; \mathrm{N} 21.5 ; \mathrm{S} 16.4\right)$.

2-Propoxy-4-methyl-5-imino-1,3,4-thiadiazoline. $5 \mathrm{~g}$ (0.0314 mole) of 2-propoxy-5amino-1,3,4-thiadiazole and $7.1 \mathrm{~g}(0.038 \mathrm{~mole})$ of methyl $p$-toluenesulphonate were mixed and heated for $45 \mathrm{~min}$ on a water-bath at $80^{\circ} \mathrm{C}$. The melt crystallized at the end of the heating. The crude product was washed with ether and acetone and recrystallized from acetonitrile. 7.3 g of 2-propoxy-4-methyl-5-imino-1,3,4-thiadiazolinium $p$-toluenesulphonate were obtained; m.p. $141-143^{\circ} \mathrm{C}$. (Found: $\mathrm{C} 45.2 ; \mathrm{H} 5.6 ; \mathrm{N} 12.2 ; \mathrm{S}$ 18.6. Calc. for $\mathrm{C}_{13} \mathrm{H}_{19} \mathrm{~N}_{3} \mathrm{O}_{4} \mathrm{~S}_{2}(345.4)$ : C 45.2; $\mathrm{H}$ 5.6; $\mathrm{N} 12.2 ; \mathrm{S} \mathrm{18.6)}$.

The hydrochloride salt was prepared from 2-propoxy-4-methyl-5-imino-1,3,4-thiadia: zolinium $p$-toluenesulphonate by dissolving this substance in $1 \mathrm{~N}$ sodium hydroxide and then extracting the solution with ethyl acetate. The ethyl acetate extract was dried and evaporated. The residue was dissolved in methanolic hydrochloric acid. The methanol was evaporated and 2-propoxy-4-methyl-5-imino-1,3,4-thiadiazolinium hydrochloride was obtained; m.p. $138-139^{\circ} \mathrm{C}$ (decomp.). (Found: C 34.0; H 5.9; Cl 16.8; $\mathrm{N} \mathrm{20.0;} \mathrm{S} \mathrm{15.3.} \mathrm{Calc.}$ for $\mathrm{C}_{8} \mathrm{H}_{12} \mathrm{ClN}_{3} \mathrm{OS}(209.7)$ : $\left.\mathrm{C} \mathrm{34.4;} \mathrm{H} 5.8 ; \mathrm{Cl} 16.9 ; \mathrm{N} \mathrm{20.0;} \mathrm{S} 15.3\right)$.

2-Propoxy-4-ethyl-5-imino-1,3,4-thiadiazoline. $5 \mathrm{~g}(0.031 \mathrm{~mole})$ of 2-propoxy-5-amino1,3,4-thiadiazole and ethyl $p$-toluenesulphonate were mixed and heated for $45 \mathrm{~min}$ at $80^{\circ} \mathrm{C}$ and then for $45 \mathrm{~min}$ at $105^{\circ} \mathrm{C}$. The clear melt obtained was washed with ether and a substance crystallized. By recrystallization from acetone-ether, $4.3 \mathrm{~g}(39 \%)$ of 2-propoxy-4-ethyl-5-imino-1,3,4-thiadiazolinium $p$-toluenesulphonate were obtained; m.p. 99-100.5 ${ }^{\circ}$. (Found: $\mathrm{C} 46.7 ; \mathrm{H} 6.1 ; \mathrm{N} \mathrm{12.1;} \mathrm{S}$ 17.6. Calc. for $\mathrm{C}_{14} \mathrm{H}_{21} \mathrm{~N}_{3} \mathrm{O}_{4} \mathrm{~S}_{2}(359.5)$ : C 46.8; H 5.9; N 11.7; S 17.8).

2-Ethoxy-4-methyl-5-nitrosimino-1,3,4-thiadiazoline. $5 \mathrm{~g}(0.0152 \mathrm{~mole})$ of 2 -ethoxy4-methyl-5-imino-1,3,4-thiadiazolinium $p$-toluenesulphonate were dissolved in $8.7 \mathrm{ml}$ of $2 \mathrm{~N}$ hydrochloric acid. $1.2 \mathrm{~g} \mathrm{(0.0174}$ mole) of sodium nitrite, dissolved in $3 \mathrm{ml}$ of water, were added dropwise to the solution at room temperature. A yellow solution was obtained and after 15 min a yellow substance precipitated. The mixture was cooled and filtered after $45 \mathrm{~min} ; 1.35 \mathrm{~g}$ of yellow crystals were obtained; m.p. $77-78^{\circ} \mathrm{C}$. By extracting the mother liquor with ether and evaporating the ether layer, a further crop of $0.25 \mathrm{~g}$ was obtained. Total yield: $1.45 \mathrm{~g}\left(56 \%\right.$ ). (Found: $\mathrm{C} 31.8 ; \mathrm{H} 4.1 ; \mathrm{N} 29.6 ; \mathrm{S} 16.9$. Calc. for $\mathrm{C}_{8} \mathrm{H}_{8} \mathrm{~N}_{4} \mathrm{SO}_{2}$ (188.2): C 31.9; H 4.3; N 29.8; S 17.0).

2-Ethoxy-4-methyl-1,3,4-thiadiazoline-5-one. $1.35 \mathrm{~g}(0.0072 \mathrm{~mole})$ of 2-ethoxy-4-methyl5-nitrosimino-1,3,4-thiadiazoline were dissolved in dioxane and the solution was heated for $2 \mathrm{~h}$. Nitrogen gas was evolved and the solution became slightly yellow. The solution was boiled with charcoal and evaporated. The residue was recrystallized from ligroin. Yield: $0.85 \mathrm{~g}(74 \%)$. M.p. $46-46.5^{\circ} \mathrm{C}$. (Found: C 30.7; H 5.2; N 21.7; S 20.2. Calc. for $\mathrm{C}_{8} \mathrm{H}_{8} \mathrm{~N}_{2} \mathrm{O}_{2} \mathrm{~S}$ (160.2): C 37.5; H 5.0; $\mathrm{N}$ 17.5; $\mathrm{S} 20.0$ ).

2-Methoxy-5-acetylamino-1,3,4-thiadiazole. $1 \mathrm{~g}$ (0.0076 mole) of 2-methoxy-5-amino1,3,4-thiadiazole and $10 \mathrm{ml}$ of acetic anhydride were mixed. The solution was heated for $45 \mathrm{~min}$. On cooling, $1.3 \mathrm{~g}$ of long white needles precipitated. The substance was recrystallized from ethanol and $1.0 \mathrm{~g}(76 \%)$ was obtained; m.p. $199-202^{\circ} \mathrm{C}$ (decomp.). The substance gave no melting-point depression with the substance obtained from 2-amino-5chloro-1,3,4-thiadiazole (I). The two substances had identical IR-spectra.

2-Ethoxy-5-acetylamino-1,3,4-thiadiazole. $10 \mathrm{~g}(0.069 \mathrm{~mole})$ of 2-ethoxy-5-amino-1,3,4thiadiazole and $50 \mathrm{ml}$ of acetic anhydride were mixed and refluxed for $1 \mathrm{~h}$. On cooling 11 g precipitated; m.p. $216.5-219.5^{\circ} \mathrm{C}$. By recrystallization $10.3 \mathrm{~g}(80 \%)$ were obtained;

Acta Chem. Scand. 18 (1964) No. 1 
m.p. 219-222 ${ }^{\circ} \mathrm{C}$. (Found: $\mathrm{C}$ 38.5; $\mathrm{H}$ 4.9; $\mathrm{N}$ 23.5; $\mathrm{S}$ 17.0. Calc. for $\mathrm{C}_{6} \mathrm{H}_{9} \mathrm{~N}_{3} \mathrm{O}_{2} \mathrm{~S}$ (187.2): C 38.5; H 4.8; N 22.5; S 17.1).

Acknowledgements. The authors are deeply indebted to Professor Arne Fredga for his kind interest in this work and to Mr. S. O. Hall for assistance with the experimental work.

\section{REFERENCES}

1. Meyer-Rohn, J. and Heidrich, L. Arzneimittel-Forsch. 11 (1961) 431.

2. Busch, M. and Limpach, O. Ber. 44 (1911) 1077.

3. Wheeler, H. and Statiropoulos, J. Am. Chem. J. 34 (1905) 117.

4. Sugii, A. J. Pharm. Soc. Japan 79 (1959) 100; Chem. Zentr. 131 (1960) 127.

5. Wangel, J. Arkiv Kemi 1 (1950) 432.

6. Ohta, H. and Ohta, M. J. Chem. Soc. Japan 78 (1957) 1; Chem. Abstr. 53 (1959) 6217.

7. Åkerblom, E. and Skagius, K. Acta Chem. Scand. 16 (1962) 1103.

8. Åkerblom, E. Acta Chem. Scand. To be published.

9. Holmberg, B. J. prakt. Chem. [2] 71 (1905) 264.

10. Bambas, L. L. The chemistry of heterocyclic compounds, Interscience Publishers, New York 1952, p. 159.

11. Sugii, A. J. Pharm. Soc. Japan 78 (1958) 306.

12. Kurzer, F. and Godfrey, L. E. A. Chem. Ind. (London) 1961107.

13. Patel, P. P. and Chakravarti, G. C. J. Indian Inst. Sci. A 13 (1930) 85.

14. Fromm, E., Layer, E. and Nerz, K. Ann. 433 (1923) 1.

15. Young, G. and Eyre, W. J. Chem. Soc. 79 (1901) 54.

16. Stolle, R. and Fehrenbach, K. J. prakt Chem. 122 (1929) 289.

17. Ban, Shoichi J. Pharm. Soc. Japan 74 (1954) 1044.

18. Guha, P. C. and Dutta, D. N. J. Indian Chem. Soc. 6 (1929) 80.

Received October 1, 1963. 